\title{
V. On the theory of evaporation
}

\section{Thos. Tredgold Esq.}

To cite this article: Thos. Tredgold Esq. (1826) V. On the theory of evaporation, Philosophical Magazine Series 1, 67:333, 45-47, DOI: 10.1080/14786442608674009

To link to this article: http://dx.doi.org/10.1080/14786442608674009

$$
\text { 曲 Published online: } 10 \text { Aug } 2009 .
$$

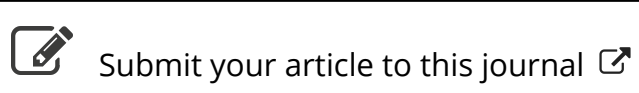

\footnotetext{
Џ Article views: 2
}

Q View related articles $\asymp$ 
As to the integral which enters into these expressions

$$
\iint \frac{\mathrm{d} s \mathrm{~d} s^{\prime}}{r^{3}}=\int \frac{\left(s-s^{\prime} \cos s\right) \mathrm{d} s^{\prime}}{\left(a^{2}+s^{\prime 2} \sin ^{2} s\right) \sqrt{a^{2}+s^{2}+s^{2}-2 s s^{\prime} \cos s}},
$$

we may obtain by the known method of integration of differentials which comprise a radix of the second order, and more easily by a particular process which I shall explain elsewhere.

V. On the Theory of Evaporation. By Thos. Tredgold, Esq. Sir, To Mr.R. Taylor.

EVAPORATION has been considerably attended to, but rather as a matter of experimental research than with the object of finding those first principles which are essential to the process. In the following inquiry it is not intended to limit it to a particular case, but simply for illustration the vapour is supposed to be from the surface of water.

When the air in contact with water is saturated with vapour, evaporation ceases, or there is an equilibrium between the powers which produce and retard the formation of vapour.

Now conceive a portion of the vapour to be abstracted from the air, then the equilibrium will be destroyed; and all other circumstances being the same, the tendency to restore the equilibrium must be proportional to the quantity of vapour removed from the previously saturated air; for no other circumstance than the weight of vapour in a given portion of air is altered.

But, the equilibrium being destroyed, evaporation commences, and the vapour cannot be formed without a constant supply of heat; therefore, to obtain this supply of heat when there is no other source than the surrounding bodies of the same temperature, the temperature of the surface where the vapour forms must be depressed, in order that heat may flow to it from the adjoining bodies, or parts of the same body; and as the heat required is proportional to the quantity of vapour formed in a given time, the depression of temperature will be proportional to that quantity.

It will also be obvious that the vapour formed will be of the elasticity corresponding to the temperature of the surface producing it, and therefore will correspond to the depressed temperature of the evaporating surface.

Let $T$ be the general temperature, $t$ the temperature of the evaporating surface at its ultimate depression, and wo the weight of vapour in grains that would saturate a cubic foot of air at 
the temperature $t$. Then, if it be ascertained by experiment that the evaporation per minute, from a surface of one foot, is $a$ when $w=1$; we have $1: a:: w: a w=$ the evaporation when the weight of vapour required for saturation, at the temperature $t$, is $r$.

Again: Let $e$ be the evaporation in grains that produces a depression of one degree of temperature, then $\mathrm{T}-t=\frac{a w}{\mathrm{t}}$; or $\mathbf{T}=t+\frac{a w}{}$. This is, however, not strictly accurate, unless the specific heat of bodies be equal at all temperatures.

The weight of a cubic foot of vapour at the temperature $60^{\circ}$, and pressure 30 inches, is 329.4 grains, and if $f$ be any other force, $30: f:: 329 \cdot 4: \frac{329 \cdot 4 f}{30}=10.98 f=$ the weight of a cubic foot of the force $f$ and temperature $60^{\circ}$. And at the temperature $t, \frac{10.98 \times 510 f}{450+t}=\frac{5600 f}{450+t}$ nearly. That is, the weight of a cubic foot of vapour at the pressure $f$ and temperature $t$ is $\frac{5600 f}{450+t}$ grains.

The expansion of dry air by saturating it with moisture appears to be equal to the addition of the same volume of vapour, of the force it would have in a vacuum at the same temperature, but both reduced to the same pressure. Therefore, if $p$ be the greater pressure or force, and $p^{\prime}$ the less, the spaces being inversely as the forces

$p: p^{\prime}:: \mathrm{V}: \mathrm{V}^{\prime}=\frac{p^{\prime} \cdot \mathrm{V}}{p}=$ the volume of the rarer fluid corresponding to the greater pressure, consequently $\frac{p^{\prime} \mathrm{V}}{p}+$ $\mathbf{V}=\mathrm{V}\left(\frac{p^{\prime}+p}{p}\right)=$ the volume as increased by expansion.

If the air be so rare that its force is less than that of steam of the same temperature, then $p^{\prime}$ indicates the force of the air; but whenever the elastic force of the air exceeds the force of steam for the same temperature, then $p=$ the force of the air.

When the forces are the same, or $p^{\prime}=p$, the volume is doubled by expansion.

General Roy's experiments, as far as they go, accord very well with this formula. The comparison of these experiments made by Mr. Daniell is not, however, quite correct. The volume of the air ought to be its volume at the same temperature as the vapour, and not increased after the operation for expansion, as he has done in his Essays, p.176. An example will render this more clear; and taking Mr. Daniell's case 
(which is to find the volume of saturated air at $32^{\circ}$, that of dry air at zero being unity), he has, $30: 30 \cdot 216:: 1: 1 \cdot 0072$, which, added to the expansion $=\cdot 07802$, gives $1 \cdot 08522$.

The process ought to be $30: 30 \cdot 216:: 1 \cdot 07802: 1 \cdot 08578$. In my own comparison I assumed that the air was saturated at zero; and though the formula gives all the numbers a little in excess, they are nearer than those resulting from $\mathrm{Mr}$. Daniell's calculations.

If these principles of the mixture of vapour with air be correct, a cubic foot of dry air, of the temperature $t$, will be saturated by $\frac{5600 f}{450+t}$ grains of vapour of the same temperature. Hence, if $x$ be the temperature of the point of deposition, and $t$ the temperature of the evaporating surface, we shall have

$$
\begin{aligned}
5600\left(\frac{f}{450+t}-\frac{f^{\prime}}{450+x}\right) & =w ; \text { and } \\
5600 a\left(\frac{f}{450+t}-\frac{f^{\prime}}{450+x}\right) & =\mathrm{E} \text {, or the evapo- }
\end{aligned}
$$

tion from a surface one foot square in grains per minute.

As $t$ is only the temperature of the evaporating surface, the general temperature will be $\mathrm{T}=t+\frac{\mathbf{E}}{e}$.

The dynamical question respecting the velocity with which vapour will rise from the evaporating surface remains to be considered, and will most likely give employment to some of your readers.

Thomas Tredgold.

P.S. My thanks are due to Candour for his references to the preceding corrections of Dr. Ure's results : I had overlooked them in the one Journal, and the other I do not regularly see.

VI. Reply to the Remarks of Mr. RiDDLE on the Double Altitude Problem. By James Bunns, Esq."

To the Editor of the Philosophical Magazine and Journal. Sir,

WR. Riddle in his concluding remarks on my solutions of 1 the problem of double altitudes, takes it for granted that "we are perfectly agreed," though there is not a single syllable in my communication (nor has he furnished a single proof)

- [We had hoped that this controversy would have been concluded in our preceding volume, and shall be well pleased if our correspondents will now allow it to terminate.-EDIr.] 